\title{
Autoimmiune Hepatitis in Children: Two Case Report
}

\author{
*Benzamin $\mathrm{M}^{1}$, Sonia $\mathrm{ZF}^{2}$, Rukunuzzaman $\mathrm{M}^{3}$, Nahid $\mathrm{KL}^{4}$, Dey BP5 , Hossen $\mathrm{K}^{6}$, Fathema $\mathrm{K}^{7}$, Khadga $\mathrm{M}^{8}$, Islam $\mathrm{MM}^{9}$
}

\begin{abstract}
Autoimmune hepatitis (AIH) is the disease of immune mediated inflammation of liver. Presentation of AIH in children is variable, ranging from acute hepatitis to cirrhosis of liver and also as only asymptomatic raised ALT. AIH can present at any age and female are more affected. Here we are presenting two cases. Case 1 presented with jaundice and H/O epistaxis, having cutaneous echymosis, hepato-splenomegaly and ascites. Case 2 was a diagnosed case of Systemic Lupus Erythematosus (SLE) presented with only persistent raised of serum ALT. Both were diagnosed as autoimmune hepatitis on the basis of positive auto antibodies, histopathology of liver tissues and exclusion of all other causes of acute and chronic hepatitis.
\end{abstract}

Keywords: Autoimmune hepatitis, children, auto antibodies

\section{INTRODUCTION}

Autoimmune hepatitis (AIH) is one of the prototype of autoimmune liver disease, it was first described in the

1. *Md. Benzamin, Resident (phase-B), Department of Pediatric Gastroenterology and Nutrition, Bangabandhu Sheikh Mujib Medical University (BSMMU), Dhaka,

Email: drmd.benzamin@yahoo.com, Cell: 01719183948

2. Zannatul Ferdous Sonia, Resident (phase-B), Department of Pediatric Gastroenterology and Nutrition, BSMMU, Dhaka, Bangladesh.

3. Md Rukunuzzaman, Professor, Department of Pediatric Gastroenterology and Nutrition, BSMMU, Dhaka.

4. Khan Lamia Nahid, Assistant Professor, Department of Pediatric Gastroenterology and Nutrition, BSMMU, Dhaka.

5. Bishnu Pada Dey, Assistant Professor, Department of Pathology, BSMMU, Dhaka.

6. Kamal Hossen, Medical Officer, Department of Pediatrics, Dhaka Medical College, Dhaka.

7. Kaniz Fathema, Resident (phase-B), Department of Pediatric Gastroenterology and Nutrition, BSMMU, Dhaka.

8. Mukesh Khadga, Resident (phase-B), Department of Pediatric Gastroenterology and Nutrition, BSMMU, Dhaka.

9. Mohammad Majharul Islam, Assistant Professor, Department of Pediatrics, Patuakhali Medical College, Patuakhai.

For Correspondence
1950. ${ }^{1-3}$ AIH is characterized by progressive inflammatory tissue damage as a result of the loss of self-tolerance. ${ }^{4} \mathrm{AIH}$ is more common in women; ratio of 3.6/1.0.5 The prevalence of $\mathrm{AIH}$ is in Scandinavia is 1 to 2 cases /100,000 populations / year with a point prevalence of 11 to 17 cases / year. ${ }^{6,7}$ In Canadian cohort, an annual incidence of pediatric AIH of 0.23 case $/ 100,000$ children. ${ }^{8}$ In Bangladesh, Benzamin et al found that, about $8 \%$ of children with chronic liver disease with hepatomegaly and or splenomegaly are due to AIH. ${ }^{9}$

Autoimmune hepatitis (AIH) is characterized biochemically by increased transaminase levels, and serologically by circulating autoantibodies and high immunoglobulin $\mathrm{G}$ ( $\mathrm{IgG}$ ) levels, histologically by interface hepatitis, in absence of known etiology. Autoimmune hepatitis can present at any age and in all ethnic groups, the peak incidence occurs at the ages of 16 to 30 years. ${ }^{5-7,10,11}$

On the basis of autoantibody AIH classified as type 1 and type 2 .

a. Type 1: Antinuclear antibody (ANA) and or anti Smooth muscle antibody (SMA). It presents at puberty $\&$ accounts for two third of cases.

b. Type 2: Anti liver kidney microsomal (LKM1) and or anti liver cytosol 1(LC1) antibody. It usually occurs in younger age $\&$ during infancy. 12,13

Autoimmune hepatitis always suspected when all cause of acute and chronic hepatitis is excluded. ${ }^{14}$

\section{CASE REPORTS}

Case 1

Choity, $8 \frac{1}{2}$ years old immunized girl, $1^{\text {st }}$ issue of non-consanguineous parents, presented with jaundice for 1 month along with anorexia, nausea, weakness and gradual abdominal distension. She also developed bleeding from nose for last 7 days. There was no $\mathrm{H} / \mathrm{O}$ abdominal pain, altered sleep pattern, abnormal behavior, any GI bleeding, rash, arthralgia, $\mathrm{H} / \mathrm{O}$ of blood transfusion, any surgical procedure, any autoimmune diseases or family history of such type of illness and no $\mathrm{H} / \mathrm{O}$ offending drug exposure. She had past $\mathrm{H} / \mathrm{O}$ jaundice and ascites 1 1/2 years back. On examination, she was moderately pale, icteric (fig 1), skin survey revealed multiple echymosis. Vitals were within 
normal limit. Anthropometrically she was well thriving. Abdominal exam revealed, hepato-splenomegaly and ascites evidenced by shifting dullness. Other systemic examinations revealed normal findings.

Investigation showed- moderate anaemia $(\mathrm{Hb} 9.6 \mathrm{gm} / \mathrm{dl})$,

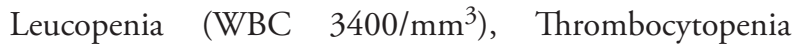
$(53000 / \mathrm{mm} 3)$, serum bilirubin increased $(6 \mathrm{mg} / \mathrm{dl})$, prolong prothrombin time (26.6 sec, INR: 2.38$)$, serum ALT was mildly raised (102 U/L), hypoalbuminemia (20 $\mathrm{gm} / \mathrm{l})$, ultrasonography of whole abdomen showed hepatomegaly with coarse parenchyma with increased parenchymal echogenicity and splenomegaly and moderate ascites. Investigations for $\mathrm{HBV}, \mathrm{HCV}$ and Wilson disease were negative. For Autoimmune hepatitis, ANA was negative, Anti- LKM1 was positive, Total IgG: $28 \mathrm{~g} / \mathrm{l}$ increase (normal 7-16 g/l), Tissue Trans-glutaminase- Ig A was negative, thyroid function test was normal and anti -Thyroglobulin $\mathrm{Ab}$ were negative. Endoscopy of upper GIT showed Grade III esophageal varices and histopathology of liver tissue revealed moderate chronic hepatitis, consistent with autoimmune hepatitis (table 1). So finally we diagnosed the case as chronic liver disease with portal hypertension with coagulopathy due to autoimmune hepatitis with grade III esophageal varices. We treated the child with Tab. Prednisolone $2 \mathrm{mg} / \mathrm{kg} /$ day and tab. Azathioprine (1-2mg/ $\mathrm{kg}$ /day) added 2 weeks later of prednisolone started. Tablet. Propranolol $(1 \mathrm{mg} / \mathrm{kg} /$ day $)$ was given as primary prophylaxis for portal hypertension.

\section{Case 2}

Bristy, a $101 / 2$ years old immunized girl, $3^{\text {rd }}$ issue of non consanguineous parents, diagnosed case of Systemic Lupus Erythematosus (SLE) for last 1 year and on treatment with tab. prednisolone $(0.6 \mathrm{mg} / \mathrm{kg} /$ day $)$ along with tab. hydroxychloroquine. She was referred to us with the complaints of persistent raised S.ALT for last six months. She had no H/O anorexia, nausea, vomiting, abdominal pain, headache, weight loss, any gastrointestinal bleeding, $\mathrm{H} / \mathrm{O}$ of blood transfusion, any surgical procedure, family history of such type of illness and no $\mathrm{H} / \mathrm{O}$ offending drug exposure. She had $\mathrm{H} / \mathrm{O}$ jaundice 2 years back. On examination she was anicteric, mildly pale, vital signs were within normal limit, anthropometrically well thriving, no feature of steroid toxicity, bed side urine albumin (BSUA) was nil and abdominal examination revealed no organomegaly. Investigation shows- mildly anaemic ( $\mathrm{Hb} 11.4 \mathrm{gm} / \mathrm{dl}$ ), S. bilirubin and prothrombin time normal, S. ALT raised (1027 U/L), Investigations for HBV, HCV, HAV, HEV and Wilson disease were negative. For Autoimmune hepatitis- Anti- LKM1: positive, anti SMA: positive, comb's test (direct and indirect) : negative. Histopathology of liver tissue was highly suggestive of autoimmune hepatitis. (table 1) So finally we diagnosed the case as Systemic Lupus Erythematosus (SLE) with Autoimmune hepatitis. We treated the child with tab. Prednisolone $2 \mathrm{mg} / \mathrm{kg} / \mathrm{day}$, tab. hydroxychloroquine and tab. Azathioprine (1-2mg/kg/day) added 2 weeks later of prednisolone started.

Table 1 : Investigation profile of case-1 (Choity) and case-2 (Bristy)

\begin{tabular}{|l|l|l|}
\hline Investigations & Case 1 & Case 2 \\
\hline Hb & $9.6 \mathrm{gm} / \mathrm{dl}$ & $11.4 \mathrm{gm} / \mathrm{dl}$ \\
\hline WBC & $3600 / \mathrm{mm} 3$ & $9000 / \mathrm{mm} 3$ \\
\hline Platelate & $53000 / \mathrm{mm} 3$ & $2,20000 / \mathrm{mm} 3$ \\
\hline S. bilirubin & $6 \mathrm{mg} / \mathrm{dl} \uparrow$ & $0.6 \mathrm{mg} / \mathrm{dl}$ \\
\hline PT & $26.6 \mathrm{sec} \uparrow$ & $13.4 \mathrm{sec}$ \\
\hline INR & $2.38 \uparrow$ & 1.04 \\
\hline S. ALT & $102 \mathrm{U} / \mathrm{L} \uparrow$ & $1027 \mathrm{U} / \mathrm{L} \uparrow$ \\
\hline S. Albumin & 20 gm/L $\downarrow$ & 43 gm/L \\
\hline USG of whole abdomen & $\begin{array}{l}\text { Liver- enlarged. Coarse parenchyma } \\
\text { with parenchymal echogenicity } \\
\text { increased and splenomegaly. vascular } \\
\text { dilatations around splenic hilar region. } \\
\text { Moderate Ascites present. }\end{array}$ & $\begin{array}{l}\text { Mild hepatomegaly with heterogenous } \\
\text { echogenicity and splenomegaly. }\end{array}$ \\
\hline
\end{tabular}


Table 1

\begin{tabular}{|c|c|c|}
\hline Investigations & Case 1 & Case 2 \\
\hline HBs Ag- & Negative & Negative \\
\hline Anti HCV & Negative & Negative \\
\hline Anti HAV IgM & Not done & Negative \\
\hline Anti HEV IgM & Not done & Negative \\
\hline S. Ceruloplasmin: & $22 \mathrm{mg} / \mathrm{dl}$ & $41 \mathrm{mg} / \mathrm{dl}$ \\
\hline $24 \mathrm{~h}$ urinary copper & $58.5 \mu \mathrm{gm} /$ day & $42.77 \mu \mathrm{gm} /$ day \\
\hline Slit lamp examination of eye & No K-F ring found & No K-F ring found \\
\hline ANA & Negative & Positive \\
\hline Anti- LKM1 & Positive & Positive \\
\hline Total IgG & $28 \mathrm{~g} / \mathrm{l} \uparrow$ & Not done \\
\hline Anti SMA & Not done & Positive \\
\hline S.F T4 & $9.94 \mu \mathrm{g} / \mathrm{dl}(\mathrm{N})$ & $7.4 \mu \mathrm{g} / \mathrm{dl}(\mathrm{N})$ \\
\hline TSH & $0.81 \mu \mathrm{IU} / \mathrm{mL}(\mathrm{N})$ & $2.1 \mu \mathrm{IU} / \mathrm{mL}(\mathrm{N})$ \\
\hline Thyroglobulin $\mathrm{Ab}$ & $<20.0 \mathrm{IU} / \mathrm{ml}(\mathrm{N})$ & $<20.0 \mathrm{IU} / \mathrm{ml}(\mathrm{N})$ \\
\hline Endoscopy of upper & Grade III esophageal & Not done \\
\hline GIT & varices seen & \\
\hline $\begin{array}{l}\text { Histopathology of Liver } \\
\text { biopsy tissue }\end{array}$ & $\begin{array}{l}\text { Portal area revealed a moderate } \\
\text { number of chronic inflammatory } \\
\text { cells. Marked piecemeal necrosis } \\
\text { and mild lobular necrosis present. } \\
\text { Bridging fibrosis is also seen. } \\
\text { Comments- Moderate chronic } \\
\text { hepatitis in consistent with } \\
\text { autoimmune Hepatitis. }\end{array}$ & $\begin{array}{l}\text { Portal area show moderate fibrosis } \\
\text { and many number of chronic } \\
\text { inflammatory cells. Marked } \\
\text { interface hepatitis and mild lobular } \\
\text { degeneration are present. Bridging } \\
\text { fibrosis is also seen. Comments- } \\
\text { highly suggestive of autoimmune } \\
\text { hepatitis. (fig 2) }\end{array}$ \\
\hline
\end{tabular}

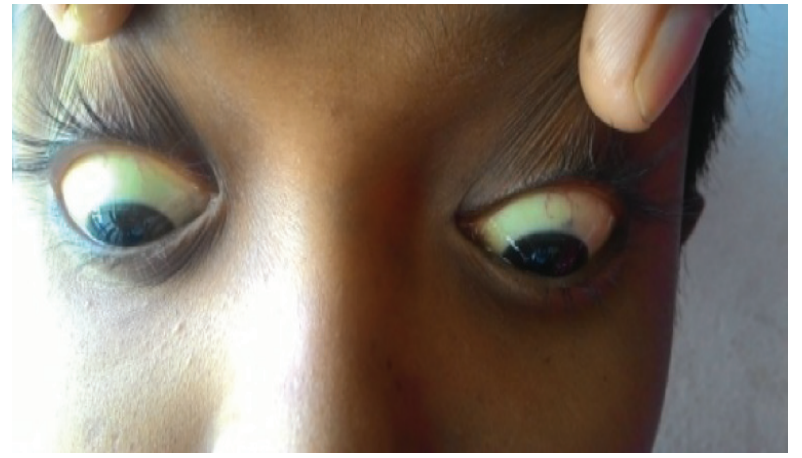

Fig.-1: Jaundice (case 1)

\section{DISCUSSION}

$\mathrm{AIH}$ has variable clinical presentation which include followings- acute presentation like viral hepatitis with malaise, nausea, anorexia, vomiting, joint pain, abdominal pain, followed by jaundice, dark urine, pale stool



Fig.-2: H\&E, 200x: Section of liver tissue showing plasma cell rich Portal inflammation, Interface hepatitis and Hepatocyte rosette formation (Marked with arrow). 
(40-50\%), fulminant hepatic failure or chronic liver disease, complication of cirrhosis and portal hypertension without history of previous liver disease and jaundice. Non specific symptoms like progressive fatigue, relapsing jaundice, amenorrhea, headache, anorexia, joint pain, abdominal pain, diarrhea, weight loss, this symptom may last for 6 month to few years before diagnosis. Incidental finding of raised ALT without sign symptoms is another presentation of AIH. [8,15-20] Our case 1 presented with jaundice, anorexia, nausea, weakness and hepatosplenomegaly, ascites and bleeding manifestation in the form of epistaxis and echymosis. Case 2 presented with raised ALT without sign symptom.

AIH can present at any age and in all ethnic groups, but it has female predominance. ${ }^{5,6,10,11}$ Our both cases are female.

Family history of autoimmune disease $(40 \%)$ is frequent in AIH. ${ }^{14}$ But in our both case there is no family history of autoimmune disease.

Diagnosis of AIH is made by combination of clinical, biochemical, immunological and histological features and exclusion of other liver diseases (like hepatitis B, C, E, Wilson disease, non alcoholic steatohepatitis (NASH) and drug induced liver disease. ${ }^{5,14,21}$

The key of diagnosis of AIH is the presence of auto antibody. Following are consider for diagnosis of AIHRaised IgG level and auto antibody found like Antinuclear antibody (ANA), anti Smooth muscle antibody (SMA), anti liver kidney microsomal (LKM1) antibody, anti liver cytosol (LC1) antibody, anti mitochondrial antibody (AMA). ${ }^{12-14}$ Our case 1 also had Anti- LKM1- positive, raised Total IgG and case 2 had ANA positive, AntiLKM1: positive, anti SMA positive.

Histological features of AIH consist of: Interface hepatitis characterized by infiltration of lymphocytes, plasma cells; which cross the limiting plate and invade the surrounding parenchyma. Connective tissue collapse resulting from hepatocyte death and expanding from the portal area into the lobule ("bridging collapse"). Hepatic regeneration with "rosette" formation. ${ }^{22-27}$ Our case 1's histtopathology of liver tissue showed portal area with a moderate number of chronic inflammatory cells, marked piecemeal necrosis and mild lobular necrosis and bridging fibrosis present. Case 2's histtopathology of liver tissue showed portal area with moderate fibrosis and many number of chronic inflammatory cells, marked interface hepatitis, mild lobular degeneration and bridging fibrosis present.
Twenty percent (20\%) of AIH patients have other autoimmune diseases at diagnosis or developed during follow up. Autoimmune thyroiditis with hypothyroidism (8-23\%), inflammatory bowel disease (18\%), celiac disease (5-10\%), hemolytic anemia, vitiligo, diabetes mellitus, urticaria pigmentosa, sjogren syndrome (SJS), SLE, glomerulonephritis, idiopathic thrombocytopenia, addison disease. ${ }^{14,15,17,28}$ Our case 1 had no autoimmune disease but case 2 was a diagnosed case of Systemic Lupus Erythematosus (SLE).

Final diagnosis of AIH was done after exclusion of liver disease (like hepatitis B, C, E, Wilson disease, NASH and drug induced liver disease) that may share serological and histological features with autoimmune hepatitis.[14] We exclude HAV,HBV,HCV , Wilson disease, NASH in both case $1 \& 2$.

After diagnosis, prompt treatment should be started. AIH is responsive to immunosuppressive drug. Treatment consists of two parts- induction of remission and maintenance phase.

Conventional treatment include prednisolone $2 \mathrm{mg} / \mathrm{kg} /$ day (maximum $60 \mathrm{mg} /$ day) and azathioprine. Prednisolone dose decreases in parallel to decline of ALT over a period of 4 to 8 weeks, maintenance dose of prednisolone will be 2.5 to $5 \mathrm{gm} /$ day. For adjustment of prednisolone dose, liver function tests should be done frequently, preferably weekly. Azathioprine (AZ) is added 0.5 to $2 \mathrm{mg} / \mathrm{kg} / \mathrm{day}$, 2 weeks after starting prednisolone.[5,14,21,29-31] In both case we started treatment with prednisolone $2 \mathrm{mg} / \mathrm{kg} /$ day. Azathioprine (AZ) is added 0.5 to $2 \mathrm{mg} / \mathrm{kg} /$ day, 2 weeks after starting prednisolone. Azathioprine will be continued in maintenance phase.

\section{CONCLUSIONS}

$\mathrm{AIH}$ has various spectrum of clinical manifestations like asymptomatic raised ALT to jaundice, ascites, hepatosplenomegaly etc. So AIH should be put in differential diagnosis of any liver disease in children. Auto antibodies and liver biopsy are the gold standard for diagnosis of AIH. Other autoimmune diseases may be associated with AIH. Long term treatment and meticulous follow up is needed for preventing disease progression.

\section{REFERENCES}

1. Mackay IR, Taft LI, Cowling DC. Lupoid hepatitis. Lancet 1956; ii: 1323-6. 
2. Joske RA, King WE. The L.E.-cell phenomenon in active chronic viral hepatitis. Lancet 1955; 269: 477-80

3. Mackay IR. Chronic active hepatitides. Front Gastrointest Res. 1975;1:142-187.

4. Fernández MIC, Hernández DR, Eugenio DEC, Palanca W, Guridi ZD, Fabián LG.Diagnosis and Treatment of Autoimmune Liver Diseases in a Tertiary Referral Center in Cuba. Current Theraputic Research. 2017; 85: 8-14.

5. Manns MP, Czaja AJ, Gorham JD, Krawitt EL, Mieli-Vergani G, Vergani D, et al.Diagnosis and management of autoimmune hepatitis. Hepatology 2010;51:2193-13.

6. Werner M, Prytz H, Ohlsson B, Almer S, Bj€ornsson E, Bergquist A, et al. Epi-demiology and the initial presentation of autoimmune hepatitis in Sweden: anationwide study. Scand J Gastroenterol 2008;43: 1232-1240.

7. Miele-Vergani G. Autoimmune hepatitis in childhood. Clin Liver Dis 2014;3:6-8.

8. Jimenez-Rivera C, Ling SC, Ahmed N, Yap J, Aglipay $\mathrm{M}$, Barrowman N, et al. Incidence and characteristics of autoimmune hepatitis. Pediatrics 2015;136 :e1237-48.

9. Md. Benzamin, Maimuna Sayeed, Md.Saidul Islam, Rubaiyat Alam, Md. Rukunuzzaman, Md Wahiduzzaman Mazumder, et al. Study of etiological profile of children presented with hepatomegaly and/or splenomegaly: An experience from Pediatric Gastroenterology Department, Bangabandhu Sheikh Mujib Medical University. Paed. Neph. J. Bang. 2018: 3(1): 9-17.

10. Boberg KM, Aadland E, Jahnsen J, Raknerud N, Stiris $\mathrm{M}$, Bell $\mathrm{H}$. Incidence and prevalence of primary biliary cirrhosis, primary sclerosing cholangitis, and autoimmune hepatitis in a Norwegian population. Scand J Gastroenterol 1998; 33:99.

11. Al-Chalabi T, Boccato S, Portmann BC, McFarlane IG, Heneghan MA. Autoimmune hepatitis (AIH) in the elderly: a systematic retrospective analysis of a large group of consecutive patients with definite $\mathrm{AIH}$ followed at a tertiary referral centre. J Hepatol 2006; 45:575.

12. Vergani D, Alvarez F, Bianchi FB, Cançado EL, Mackay IR, Manns MP, et al. Liver autoimmune serology: a consensus statement fromthe committee for autoimmune serology of the International Autoimmune Hepatitis Group. J Hepatol 2004;41: 677-83.

13. Villalta D, Girolami E, Alessio MG, Sorrentino MC, Tampoia M, Brusca I, et al. Autoantibody profiling in a cohort of pediatric and adult patients with autoimmune hepatitis. J Clin Lab Anal 2016;30:41-6.

14. Mieli-Vergani G, Vergani D, Baumann U, Czubkowski P, Debray D, Dezsofi A, et al. Diagnosis and Management of Pediatric Autoimmune Liver Disease: ESPGHAN Hepatology Committee Position Statement. JPGN 2018;66: 345-360.

15. Gregorio GV, Portmann B, Karani J, Harrison P, Donaldson PT, Vergani V, et al. Autoimmune hepatitis/sclerosing cholangitis overlap syndrome in childhood: a 16-year prospective study. Hepatology 2001;33:544-53.

16. Di Giorgio A, Bravi M, Bonanomi E, Alessio, G, Sonzogni, A, Zen Y, et al. Fulminant hepatic failure of autoimmune aetiology in children. J Pediatr Gastroenterol Nutr 2015;60:159-64.

17. Gregorio GV, Portmann B, Reid F, Donaldson PT, Doherty DG, McCartney M, et al. Autoimmune hepatitis in childhood: a 20-year experience. Hepatology 1997;25:541-7.

18. MieliVergani G, Heller S, Jara P, Vergani D, Chang $\mathrm{MH}$, Fujisawa T, et al. Autoimmune hepatitis. J Pediatr Gastroenterol Nutr 2009;49:158-64.

19. Ramachandran J, Sajith KG, Pal S, Rasak JV, Prakash JA, Ramakrishna B, et al. Clinicopathological profile and management of severe autoimmune hepatitis. Trop Gastroenterol. 2014;35:25-31.

20. Brissos J, Carrusca C, Correia M, Cabral J. Autoimmune hepatitis: trust in transaminases. BMJ Case Rep 20142014.

21. European Association for the Study of the L. EASL Clinical Practice Guidelines: Autoimmune hepatitis. J Hepatol 2015;63:971-1004.

22. Czaja AJ, Carpenter HA. Autoimmune hepatitis. In: Macsween RNM, Burt AD, Portmann BC, eds. 
Pathology of the Liver. 4th Edition Churchill Livingstone; 2001:415-34.

23. Miao Q, Bian Z, Tang R, Zhang H, Wang Q, Huang $S$, et al. Emperipolesis mediated by CD8 T cells is a characteristic histopathologic feature of autoimmune hepatitis. Clin Rev Allergy Immunol 2015;48: 226-35.

24. de Boer YS, van Nieuwkerk CM, Witte BI, Mulder CJJ, Bouma G, et al. Assessment of the histopathological key features in autoimmune hepatitis. Histopathology 2015;66:351-62.

25. Kumari N, Kathuria R, Srivastav A, Narendra K, Ujjal P, Surender K Y. Significance of histopathological features in differentiating autoimmune liver disease from nonautoimmune chronic liver disease in children. Eur J Gastroenterol Hepatol 2013;25: 333-7.

26. Tucker SM, Jonas MM, Perez-Atayde AR. Hyaline droplets in Kupffer cells: a novel diagnostic clue for autoimmune hepatitis. Am J Surg Pathol 2015;39: $772-8$.

27. Tiniakos DG, Brain JG, Bury YA. Role of histopathology in autoimmune hepatitis. Dig Dis 2015; 33(suppl 2):53-64.

28. Wong GW, Heneghan MA. Association of extrahepatic manifestations with autoimmune hepatitis. Dig Dis 2015;33(suppl 2):25-35

29. Mieli-Vergani G, Vergani D. Paediatric autoimmune liver disease. Arch Dis Child 2013;98:1012-7.

30. Floreani A, Liberal R, Vergani D, Mieli-Vergani G. Autoimmune hepatitis: contrasts and comparisons in children and adults - a comprehensive review. J Autoimmun 2013;46:7-16.

31. Czaja AJ, Bianchi FB, Carpenter HA, Krawitt EL, Lohse AW, Manns MP, et al. Treatment challenges and investigational opportunities in autoimmune hepatitis. Hepatology 2005;41:207-15. 